Instructions for authors, subscriptions and further details:

\title{
http://mcs.hipatiapress.com
}

\section{Key Concepts in Gender Studies}

Patricia Melgar Alcantud ${ }^{1}$

1) Universitat de Girona, Spain

Date of publication: June $21^{\text {th }}, 2018$

Edition period: June 2018-October 2018

To cite this article: Melgar, P. (2018). Key Concepts in Gender Studies.

[Review of the book]. Masculinities and Social Change, 7(2), 213-214. doi:

10.17583/MCS.2018.3574

To link this article: http://dx.doi.org/10.4471/MCS.2018.3574

\section{PLEASE SCROLL DOWN FOR ARTICLE}

The terms and conditions of use are related to the Open Journal System and to Creative Commons Attribution License (CC-BY). 


\section{Reviews (II)}

Pilcher, J., \& Whelehan, I. (2016). Key concepts in gender studies. London: Sage.

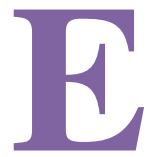

Los estudios de género tienen una trayectoria muy larga en el ámbito de la investigación. Esta trayectoria ha ido acompañada de la definición de diferentes conceptos que han marcado su historia. En el presente libro se presenta una recopilación muy interesante y muy bien artículada de muchos de estos conceptos centrales en los "gender studies". En total son 50 conceptos que se recopilan y que se encuadran en diferentes ámbitos. En esta review vamos a apuntar algunos de estos que aportan elementos innovadores y/o pocos conocidos sobre los estudios de género.

Uno de estos conceptos que queremos destacar es ageing que aporta un elemento interesante al análisis de la discriminación de género. De hecho, incorpora la perspectiva de la interseccionalidad como un elemento explicativo a la doble discriminación que padecen las mujeres que están en las cohortes de mayor edad. Otro concepto que introducen las autoras del libro poco referenciado por la literatura feminista es cyborg. Para algunas feministas, como Haraway (1991) que escribió el Manfiesto Cyborg, la existencia de cyborgs implica un cuestionamiento importante a los relaciones sociales tradicionales que muy a menudo son perpetuadoras del patriarcado.

Otro concepto interesante a considerar por su actualidad en las reivindiaciones femininstas es "girl power". En el libro se referencia a dos icónos pop de finales del siglo XX y principios del XXI como las Spice Girls y Madonna. De hecho, en la entrada del libro se menciona que fueron las primeras que lo utilizaban como slogan en sus campañas de marketing. De este modo, girl power se interpreta como aquellas mujeres que "toman el 
control" de sus vidas y de sus propias decisiones y con ideas muy claras sobre su sexualidad.

Por último quiero subrayar, por la relación con la revista Masculinities and Social Change, la entrada sobre el concepto de masculinidades. En esta entrada se referencian diferentes estudios y contribuciones teóricas claves en los men's studies, como los aportados por Connell y Bly. Sin embargo, es relevant apuntar, por su reciente publicación, el concepto de masculinidades híbridas. Dichas masculinidades se caracterizan por alejarse del modelo hegemónico, ya que incorporan la terntura como características intrínseca, aunque los creadores del concepto Bridges y Pascoe (2014) plantean que no son una alternativa real. No son una alternativa porque no son un cambio profundo en la consecuión de la igualdad de género, sino que significan únicament una remodelación a nuestros días del modelo tradicional.

\section{References}

Bridges, T., \& Pascoe, C. J. (2014). Hybrid masculinities: New directions in the sociology of men and masculinities. Sociology Compass, 8(3), 246258. doi: https://doi.org/10.1111/soc4.12134

Haraway, D. (1991). A cyborg manifesto. London: Free Association Books.

Patricia Melgar Alcantud, Universitat de Girona. patricia.melgar@udg.edu 